Case reports

\title{
Familial congenital laryngeal abductor paralysis: different expression in a family with one male and three females affected
}

\author{
A Schinzel, Erika Hof, P Dangel, Wendy Robinson
}

\begin{abstract}
$A$ brother and two sisters of remotely consanguineous parents had congenital laryngeal abductor paralysis and moderate mental retardation. In the two older sibs, mental deficiency could have resulted from birth asphyxia, but the youngest girl was already microcephalic at birth and had no apparent asphyxia. The mother, who was healthy and of normal intelligence, was found on laryngoscopy to have unilateral laryngeal abductor paralysis. This is the first family with both mentally retarded and nonretarded affected members with congenital laryngeal abductor paralysis. Inheritance is most likely autosomal dominant with variable expression, but autosomal recessive inheritance, with both parents carriers and the mother an affected homozygote, and $\mathbf{X}$ linked inheritance are also possible.
\end{abstract}

Familial congenital laryngeal abductor paralysis was first described by Plott $^{1}$ in 1964. This family and a later one reported by Watters and Fitch ${ }^{2}$ showed probable $\mathrm{X}$ linked inheritance with mild to moderate mental retardation in all of the affected whose development could be tested. Four pedigrees consistent

Institut für Medizinische Genetik der Universität Zürich, Rämistrasse 74, CH-8001 Zürich, Switzerland.

A Schinzel, W Robinson

Department of Oto-Rhino-Laryngology, University of Zürich, Switzerland.

E Hof

Department of Paediatrics, University of Zurich, Switzerland.

E Hof, $P$ Dangel

Correspondence to Professor Schinzel.

Received for publication 22 December 1989.

Revised version accepted for publication 12 April 1990. with autosomal dominant inheritance have also been reported. ${ }^{3-7}$ Intelligence was normal in all affected members of these families.

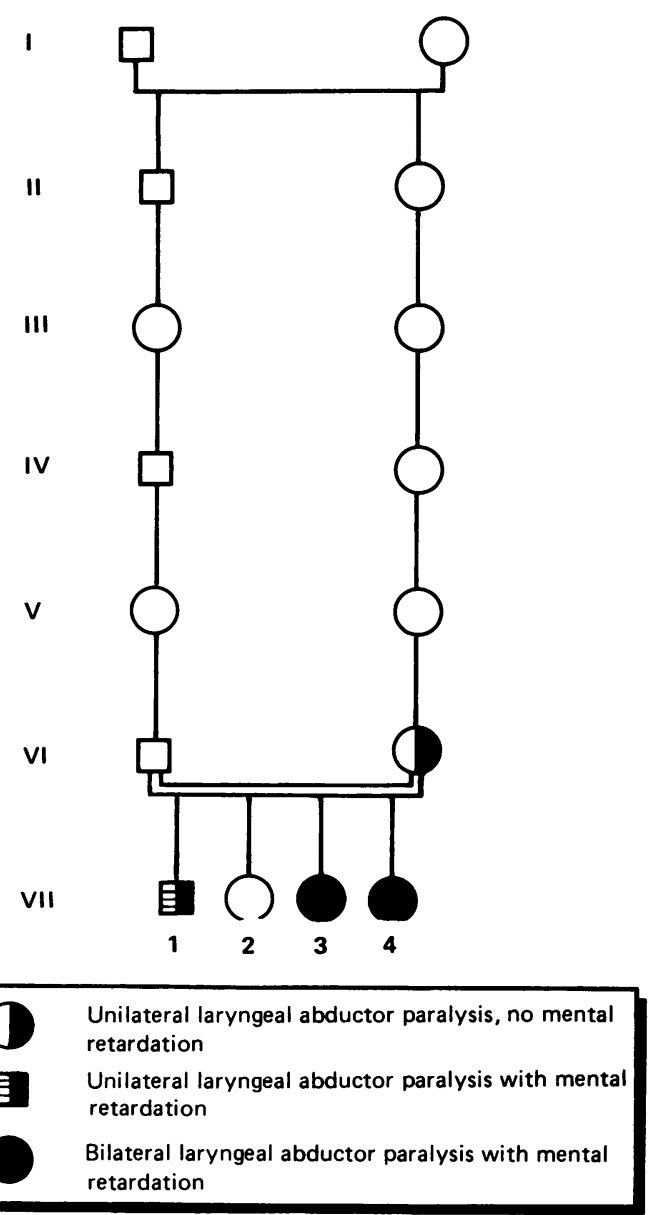

Family pedigree. 
We present here a family with four members affected with congenital laryngeal abductor paralysis (two unilaterally and two bilaterally affected), of whom only three are mentally retarded. The pedigree does not allow a clear determination of the mode of inheritance.

\section{Case reports}

The pedigree is shown in the figure. The parents are remotely related to each other through great great grandparents who are sibs. VII.1 and VII.3 suffered from moderate asphyxia at birth. VII.1 has delayed fine motor skills and coordination, while VII.3 is especially retarded in language. VII.4 had no substantial birth asphyxia, but was microcephalic at birth. Congenital laryngeal stridor was present in all affected sibs. All three were intubated after birth and underwent laryngoscopy and tracheostomy at 2 months. The tracheostomy was closed at 11 months in VII. 1 and at 1 year in VII.3. VII.4 underwent removal of the left vocal cord muscle at the age of 1 year. All three sibs developed bronchiectasis by the age of 3 years. Laryngoscopy of the parents was performed after the birth of VII.3; the finding of unilateral laryngeal abductor paralysis in the mother was unsuspected. She has never had stridor nor was there birth asphyxia or other problems at birth. She and her husband were not formally tested, but were judged to be of average intelligence. No CT or MRI scans of the brain have been performed in any member of the family, but neurological examinations showed no abnormality in any of them.

\section{Discussion}

Familial laryngeal abductor paralysis was first reported by Plott ${ }^{1}$ in 1964 in four brothers of normal parents. One boy died soon after birth and the three others suffered from moderate mental retardation, with IQs of around 55 in the $51 / 2$ and 4 year olds and of 73 in the 2 year 5 month old. Paralysis was bilateral in all three patients. The author favoured $\mathrm{X}$ linked recessive inheritance; however, autosomal recessive inheritance cannot be formally excluded.

Subsequently, only one additional family with congenital laryngeal abductor paralysis with possible $\mathrm{X}$ linked inheritance has been reported. Watters and Fitch ${ }^{2}$ described three affected males, two brothers and their first cousin once removed. The proband (the cousin) suffered from severe birth asphyxia and had severe mental retardation; laryngoscopy showed bilateral laryngeal abductor paralysis. Of the two affected brothers, one died shortly after delivery from severe asphyxia. The older brother had congenital laryngeal stridor and was blind and severely mentally retarded. Laryngoscopy was not done in either of the latter two patients.
Congenital bilateral laryngeal abductor paralysis with an autosomal dominant pattern of inheritance was reported by Gacek, ${ }^{3}$ Mace et $a l^{4}{ }^{4}$ Morelli et $a l^{56}$ (three generations with at least four affected), and Brunner and Herrmann ${ }^{7}$ (congenital paralysis of the laryngeal abductor and adductor in a mother and one son, congenital paralysis of the laryngeal abductor only in her two daughters). All affected members of all these families were mentally normal and thus could reproduce. Therefore, all affected members in families with a autosomal dominantly inherited congenital laryngeal abductor paralysis reported so far had normal intelligence, whereas all affected members in $\mathrm{X}$ linked pedigrees were mentally retarded.

Our family is different from all of the above mentioned families: it contains, within one pedigree, uni- and bilaterally affected and intellectually normal and retarded members. Although we do not know whether the unilateral paralysis in the mother was present from birth, postnatal onset seems very unlikely. Stridor was never reported in her.

$\mathrm{X}$ linked recessive inheritance can be excluded in this pedigree but other modes of inheritance cannot. $\mathrm{X}$ linked dominant or semidominant inheritance, although unlikely, is not excluded although the male is less rather than more severely affected than his two sisters. The most likely mode of inheritance seems to be autosomal dominant with variable expression, as this is both consistent with the pedigree and has been previously reported for the disease, although not in association with mental retardation. Mental retardation in the two older affected sibs could be attributed to birth asphyxia; however, there is no evidence for asphyxia in the youngest daughter who was already microcephalic at birth. Unilateral laryngeal abductor paralysis in the mother is unlikely to be fortuitous; however, a postzygotic somatic mutation would be a possibility that could explain this as well as her normal intelligence. If the condition in our family is caused by an autosomal dominant gene, parental consanguinity must be fortuitous.

1 Plott D. Congenital laryngeal-abductor paralysis due to nucleus ambiguus dysgenesis in three brothers. $N$ Engl F Med 1964;271: 593-7.

2 Watters GV, Fitch N. Familial laryngeal abductor paralysis and psychomotor retardation. Clin Genet 1973;4:429-33.

3 Gacek RR. Hereditary abductor vocal cord paralysis. Ann Otol 1976;85:90.

4 Mace M, Williamson E, Worgan D. Autosomal dominantly inherited abductor laryngeal paralysis - a new syndrome with a suggestion of linkage to HLA. Clin Genet 1978;14:265-70.

5 Morelli G, Mesolella C, Cavaliere ML, Stabile M, Ventruto V. Autosomal dominant inheritance of Gerhardt's syndrome in three generations of a family. F Med Genet 1980;17:325.

6 Morelli G, Mesolella C, Costa F, Testa B, Ventruto V, Santulli B. Familial laryngeal abductor paralysis with presumedautosomal dominant inheritance. Ann Otol Rhinol Laryngol 1982;91:323-4.

7 Brunner FX, Herrmann IF. Die familiär gehäufte Rekurrensparese, ein genetisch fixiertes Syndrom-erneut Hinweise für eine Kopplung des Defektgens mit dem HLA-System. Laryngol Rhinol Otol 1982;61:186-8. 